\title{
Production of Heat-Resistant EP220 and EP929 Alloys by High-Temperature Treatment of Melt
}

\author{
A. G. Tyagunov ${ }^{a}$, E. E. Baryshev ${ }^{a}$, G. V. Tyagunov ${ }^{a}$, and V. B. Mikhailov ${ }^{b}$ \\ ${ }^{a}$ Ural Federal University \\ ${ }^{b}$ OAO Zlatoustovskii Metallurgicheskii Zavod \\ Received July 5, 2013
}

\begin{abstract}
Analysis of samples of EP220 and EP929 alloys in the liquid and solid state permits the determination of the parameters for high-temperature melt treatment in their production. On heating to specific temperatures, the structure of the liquid alloys moves closer to equilibrium. In the solidification of such melt, the cast metal formed is characterized by finer grain structure, greater dispersity of the dendrites, and greater density and microhardness of the matrix. Industrial adoption of high-temperature melt treatment will improve plasticity, increase the long-term strength, and boost the product yield. The proposed technology does not fully utilize the potential of the alloy structure obtained after high-temperature melt treatment. The effect may be amplified by more prolonged holding of the melt at $1650^{\circ} \mathrm{C}$ and by optimization of the vacuumarc heating, deformation, and heat treatment, in the light of the structural changes in the experimental samples of solid metal.
\end{abstract}

Keywords: melt, physical properties, structural transformations, high-temperature melt treatment, solidification, cast metal, grain structure, mechanical properties

DOI: $10.3103 / \mathrm{S} 0967091213090155$

The properties of heat-resistant alloys may be improved by high-temperature melt treatment during smelting or remelting [1-3]. This technology is of interest in the production of billet for subsequent treatment-in particular, in the manufacture of electrodes used in vacuum arc remelting.

As a rule, EP220 and EP929 alloys are produced within 1-t induction furnaces, in fused-magnesite crucibles. The maximum temperature is no more than $1600^{\circ} \mathrm{C}$. The batch contains $40 \%$ plant waste and alloying composites. The metal is cast through a tundish in semicontinuous-casting machines. Each ingot is cut into five different parts, as electrodes for subsequent vacuum arc remelting. The quality is monitored in the final rod after appropriate processing and heat treatment.

EP220 and EP929 alloys are hard to deform and have been alloyed to the limit (Table 1); the degree of alloying exceeds $40 \%$ (Table 2 , coefficient $K_{1}$ ). Therefore, their properties cannot be further improved by means of alloying, since that would lead to loss of deformability.

To determine the parameters of high-temperature melt treatment in the production of EP220 and EP929 alloys, samples are investigated in liquid and solid states.

The temperature dependence of the kinematic viscosity $v$ and electrical resistivity $\rho$ is shown in Fig. 1. The results indicate that the molten batch is in dise- quilibrium and that there is scope for changing its structure by heating above the critical temperature $t_{\mathrm{cr}}$.

Polytherms of the electrical resistance are particularly informative: they allow us to track the step-bystep changes in the melt structure. In the range from $t_{\mathrm{L}}$ to $t_{\text {an }}$ (Fig. 1), $\rho$ hardly increases, because the scattering of the conduction electrons at the thermal oscillation of the atoms increases with increase in the temperature (phonon scattering). To some extent, this range corresponds to thermal stability of the primary structure formed after batch melting: $\Delta t_{\mathrm{ts}}=t_{\mathrm{an}}-t_{\mathrm{L}}$.

Evidently, $\Delta t_{\text {ts }}$ will depend on various factors-in particular, the chemical composition. On the basis of Table 2 and Fig. 2, we see that the temperature range where the melt is thermally stable after batch melting rises with decrease in the alloying coefficient $K_{1}$ (the sum of all the alloying elements), in the coefficient $K_{2}$ (the sum of elements strengthening the solid solution), and in $K_{4}$ (the sum of carbide-forming elements). The alloys have similar values of $K_{3}$, which characterizes the formation of strengthening $\gamma^{\prime}$ phase, and therefore it has no influence on $\Delta t_{\mathrm{ts}}$.

Between $t_{\mathrm{an}}$ and $t_{\mathrm{h}}$, the structure of the melt changes rapidly, as it moves closer to equilibrium. Correspondingly, the atomic interaction becomes stronger, and the electrical resistance increases. Like $t_{\text {an }}$, the hysteresis temperature $t_{\mathrm{h}}$ increases with decrease in $K_{1}, K_{2}$, and 
Table 1. Composition of heat-resistant alloys, wt \%

\begin{tabular}{c|c|c|c|c|c|c|c|c|c|c}
\hline Alloy & $\mathrm{Ni}$ & $\mathrm{C}$ & $\mathrm{Cr}$ & $\mathrm{Co}$ & $\mathrm{Mo}$ & $\mathrm{W}$ & $\mathrm{Al}$ & $\mathrm{Ti}$ & $\mathrm{B}$ & $\mathrm{Fe}$ \\
\hline EP929 & Balance & 0.07 & 11.0 & 13.3 & 5.0 & 5.5 & 4.0 & 1.8 & 0.02 & - \\
EP220 & Balance & 0.08 & 10.5 & 15.0 & 6.6 & 6.0 & 4.4 & 2.5 & 0.02 & $\leq 3.0$ \\
\hline
\end{tabular}

Table 2. Some characteristic temperatures and coefficients for molten EP220 and EP929 heat-resistant alloys

\begin{tabular}{c|c|c|c|c|c|c|c|c|c}
\hline Alloy & $t_{\mathrm{an}},{ }^{\circ} \mathrm{C}$ & $t_{\mathrm{h}},{ }^{\circ} \mathrm{C}$ & $t_{\mathrm{cr}},{ }^{\circ} \mathrm{C}$ & $\Delta t_{\mathrm{ts}}$ & $\Delta t_{\mathrm{ir}}$ & $K_{1}$ & $K_{2}$ & $K_{3}$ & $K_{4}$ \\
\hline EP929 & 1560 & 1660 & 1750 & 130 & 100 & 41 & 25 & 11 & 31.5 \\
EP220 & 1470 & 1600 & 1650 & 60 & 130 & 48 & 31.5 & 12 & 38 \\
\hline
\end{tabular}

$K_{3}$, but the temperature range of intense restructuring $\Delta t_{\mathrm{ir}}=t_{\mathrm{h}}-t_{\mathrm{an}}$ shrinks.

In the interval $\Delta t_{\text {ir }}$, partial restoration of fragments of the primary structure is possible on cooling. Only heating above $t_{\mathrm{cr}}$ completes the formation of equilibrium structure. The critical temperature is determined by the coefficients $K_{1}, K_{2}$, and $K_{3}$ : as they decrease, $t_{\mathrm{cr}}$ increases (Fig. 2). The importance of heating the melt to or above the critical temperature is confirmed by X-ray structural data.

The experimental data obtained indicate that, at $1500^{\circ} \mathrm{C}$, the initial state of the melt is microheterogeneous. Therefore, the second intensity peak of the $\mathrm{X}$-ray scattering, corresponding to the presence of fine structure, takes triplet form. The subpeaks observed are reflexes from different structural components of the melt. Holding the melt for $1 \mathrm{~h}$ at $1500^{\circ} \mathrm{C}$ does not change the structure. However, the melt structure changes on heating to $1700^{\circ} \mathrm{C}$ with subsequent cooling to $1500^{\circ} \mathrm{C}$. The fine structure of the second maximum disappears; it becomes smooth. That corresponds to

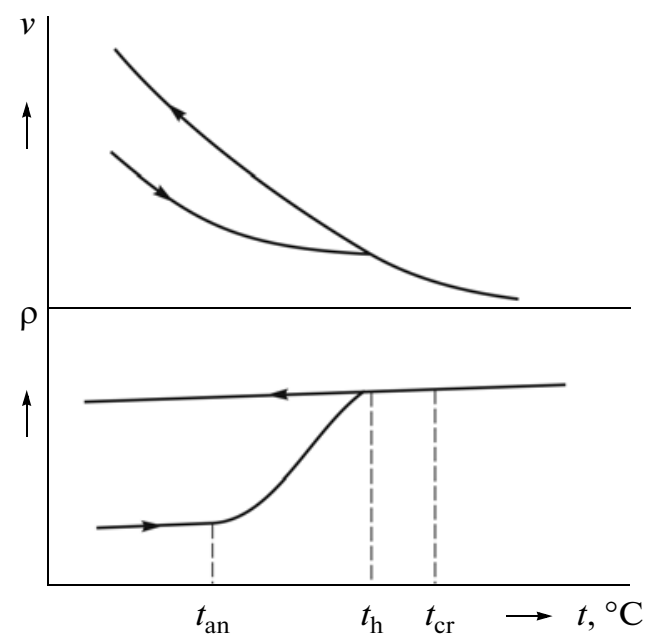

Fig. 1. Polytherms of the kinematic viscosity $v$ and electrical resistivity $\rho$ and characteristic temperatures of heatresistant alloys. melt structure that is more uniform and closer to equilibrium.

The influence of the melt structure before solidification on the cast structure of the metal is investigated in laboratory melts produced in the following conditions:

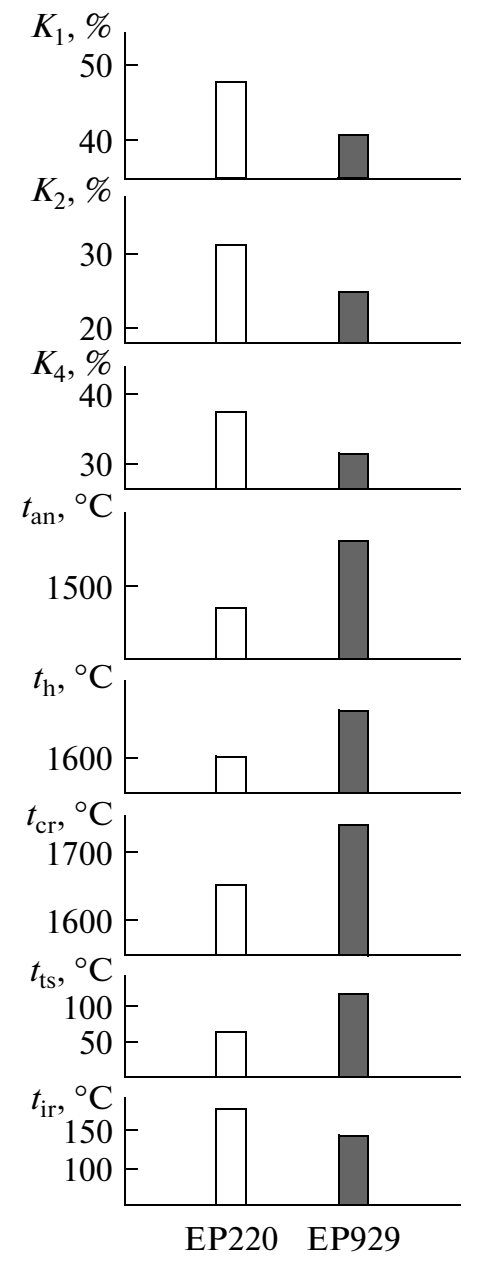

Fig. 2. Some characteristic temperatures and coefficients for molten EP220 and EP929 heat-resistant alloys. 
Table 3. Conditions in model melts and microstructure of EP220 alloy samples

\begin{tabular}{l|c|c|c|c|c|c}
\hline \multicolumn{1}{c}{ Characteristic } & \multicolumn{5}{c}{ Melt } \\
\cline { 2 - 7 } & 1 & 2 & 3 & 4 & 5 & 6 \\
\hline Specified initial temperature $t_{\mathrm{sp}},{ }^{\circ} \mathrm{C}$ & 1600 & 1600 & 1660 & 1700 & 1750 & 1660 \\
Holding time at $t_{\mathrm{sp}}$, min & 10 & 10 & 10 & 10 & 10 & 20 \\
Wetting angle of crucible walls by melt, deg & 115 & 111 & 81 & 103 & 98 & 87 \\
Distance between second-order axes $d_{\mathrm{II}}, \mu \mathrm{m}$ & 77.7 & 75.6 & 61.0 & 66.3 & 58.5 & 59.6 \\
Microhardness $\mu, \mathrm{MPa}$ & 4200 & 4260 & 4890 & 4470 & 4640 & 5280 \\
\hline
\end{tabular}

(1) heating of alloy samples of grade composition to specific temperature $t_{\mathrm{sp}}$;

(2) holding at $t_{\mathrm{sp}}$ for 10 or $20 \mathrm{~min}$;

(3) cooling to $1570^{\circ} \mathrm{C}$ at $10^{\circ} \mathrm{C} / \mathrm{min}$;

(4) holding at $1570^{\circ} \mathrm{C}$ for $10 \mathrm{~min}$;

(5) cooling to $1250^{\circ} \mathrm{C}$ at $20^{\circ} \mathrm{C} / \mathrm{min}$;

(6) shutdown of the furnace.

Table 3 presents the conditions employed in the six cases considered; in all, 18 melts are studied.

Analysis of Table 3 indicates that the state of the melt is related to its wetting angle at the crucible walls: with increase in the wetting angle, the probability of surface defects in the ingot increases.

The macrostructure of the metal obtained with melt heating to $1660^{\circ} \mathrm{C}$ is preferable in terms of the wetting angle, the form of the shrinkage pores, and the position of the shrinkage defects.

If the melt is heated above $t_{\mathrm{cr}}$, its microstructure changes. For example, in cases 1 and 2 , large randomly distributed dendrites are seen (Fig. 3a). With increase in the melt temperature to $1660^{\circ} \mathrm{C}$ in case 3 (Table 3), the dispersity of the dendrites increases, but the large-grain structure is retained (Fig. 3b). The difference between samples 2 and 6 is greatest. After heating the melt to $1660^{\circ} \mathrm{C}$ and holding for around $20 \mathrm{~min}$, the dendrites in the cast metal become smaller but they are oriented in the direction of first- and second-order axes (Fig. 3c).
In case 6 , the microhardness is greatest (Table 3); it is increased by $23 \%$. By analogy with other heat-resistant alloys, we may evidently conclude that the significant increase in matrix microhardness is due to increase in the quantity and dispersity of secondary $\gamma$ 'phase.

Thus, the results indicate intense transition of the melt structure to the equilibrium state on heating to the critical temperature. That significantly changes the structure and properties of the cast metal. The effect of high-temperature heating $\left(\sim 1660^{\circ} \mathrm{C}\right)$ is intensified on holding for up to $20 \mathrm{~min}$. Further increase in temperature does not markedly affect the structure and properties of the cast metal.

On the basis of the experimental data, we may develop an experimental technology for melt production in an industrial induction furnace. After melting the usual batch materials, the melt is heated to 1650$1660^{\circ} \mathrm{C}$, with holding for $10 \mathrm{~min}$. Then the melt is cooled to $1550^{\circ} \mathrm{C}$ in $5-10 \mathrm{~min}$. After adding ferroboron and nickel-magnesium alloy, the melt is heated before discharge to $1570-1590^{\circ} \mathrm{C}$. The standard technology is used for all subsequent operations, including discharge, casting, treatment of the ingots, vacuumarc remelting, deformational processing of the alloy, and heat treatment.

The quality of the metal is monitored in the cast state and after subsequent treatment. The size and position of the shrinkage defects permit trimming of the ingots by $30 \mathrm{~cm}$. Surface defects (crust anomalies,
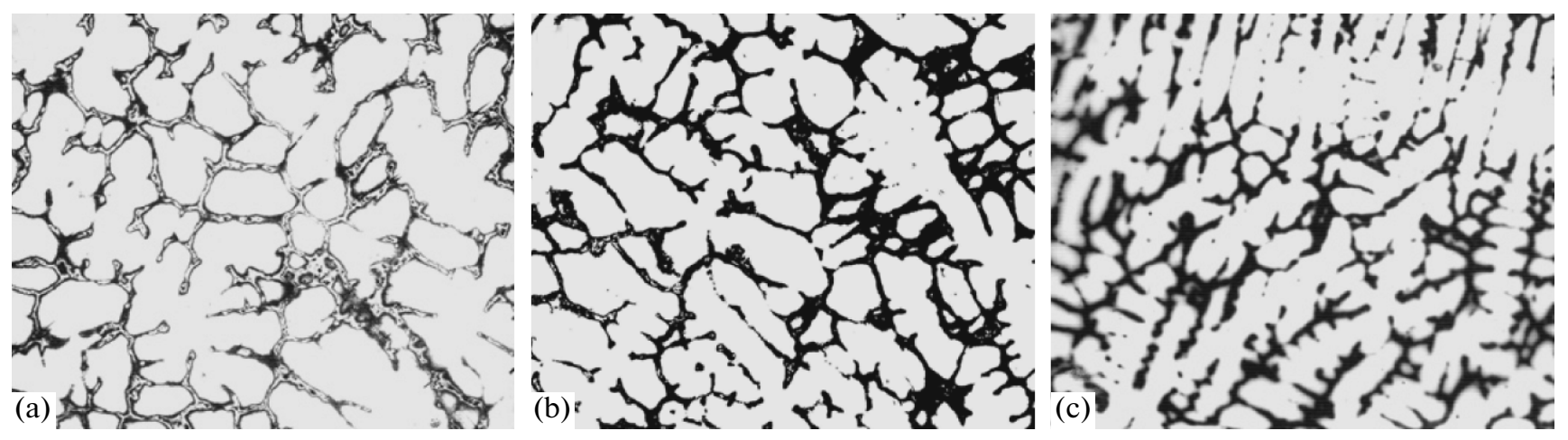

Fig. 3. Structure of model samples of EP220 alloy corresponding to cases 1 (a), 4 (b), and 6 (c) in Table 3. 
Table 4. Properties of EP220 alloy

\begin{tabular}{|c|c|c|c|c|c|c|}
\hline \multirow{2}{*}{ Samples } & \multicolumn{3}{|c|}{ Mechanical properties at $950^{\circ} \mathrm{C}$} & \multirow{2}{*}{$\begin{array}{l}\text { Holding time at } \\
900^{\circ} \mathrm{C} \text { with a } \\
280-\mathrm{MPa} \text { load, } \mathrm{h}\end{array}$} & \multirow{2}{*}{$\begin{array}{l}\text { Microhardness } \\
\text { of matrix, MPa }\end{array}$} & \multirow{2}{*}{$\begin{array}{l}\text { Density, } \\
\mathrm{kg} / \mathrm{m}^{3}\end{array}$} \\
\hline & $\sigma_{\mathrm{B}}, \mathrm{MPa}$ & $\delta, \%$ & $\varphi, \%$ & & & \\
\hline Experimental & 578 & 18.1 & 19 & 90 & 5450 & 8397 \\
\hline Industrial & 573 & 13.6 & 10 & 76 & 5110 & 8364 \\
\hline Technical specifications & 492 & 6 & 9 & 50 & - & - \\
\hline
\end{tabular}

scratches, and bubbles) are very rare on the experimental samples and do not extend beyond $3 \mathrm{~mm}$ into the depth. The high quality of the ingot surface permits increase in the yield of cast metal for subsequent processing by $4 \%$.

After rolling to bar, the experimental metal is in full compliance with the technical specifications. The strength $\sigma_{\mathrm{B}}$, plasticity ( $\delta$ and $\varphi$ ), time to failure at $900^{\circ} \mathrm{C}$ with a $280-\mathrm{MPa}$ load, matrix microhardness, and density considerably exceed the mean values for industrial metal (Table 4). Note also the stability of the test results for metal from different experimental melts, in terms of all the characteristics considered, in contrast to industrial melts.

Thus, heating to specific temperatures results in more-equilibrium structure of liquid heat-resistant alloys. In the solidification of such melt, the cast metal formed is characterized by finer grain structure, greater dispersity of the dendrites, and greater density and microhardness of the matrix. Industrial adoption of high-temperature melt treatment will improve plasticity, increase the long-term strength, and boost the product yield.
Note that the proposed technology does not fully utilize the potential of the alloy structure obtained after high-temperature melt treatment. The effect may be amplified by more prolonged holding of the melt at $1650^{\circ} \mathrm{C}$ and by optimization of the vacuum-arc heating, deformation, and heat treatment, in the light of the structural changes in the experimental samples of solid metal.

\section{REFERENCES}

1. Baum, B.A., Khasin, G.V., Tyagunov, G.V., et al., Zhidkaya stal' (Liquid Steel), Moscow: Metallurgiya, 1984.

2. Baryshev, E.E., Tyagunov, A.G., and Stepanova, N.N., Vliyanie struktury rasplava na svoistva zharoprochnykh splavov $v$ tverdom sostoyanii (Influence of the Melt Structure on the Properties of Solid Heat-Resistant Alloys), Yekaterinburg: UrO RAN, 2010.

3. Baum, B.A., Tyagunov, G.V., Baryshev, E.E., and Tsepelev, V.S., Stal', 1996, no. 6, pp. 16-20.

Translated by Bernard Gilbert 